\title{
HOE KAN DAAR DIKWELS OOR DIE KATEGISMUS GEPREEK WORD SONDER OM DIE MENSE WEG TE JAAG? ${ }^{\wedge}$
}

\section{Inleiding:}

1.1. Die formulering van die onderwerp is nie van my nie maar is "voorgeskryf". Die vraag - hoe kan dikwels oor die Kategismus gepreek word - kan mens sonder meer negatief beantwoord: mens kan nie. Op grond van die reformatoriese opvatting van die verhouding Skrif en belydenis en op grond van die Bybelse vulling en reformatoriese herontdekking van die predikingskategorie, préék mens nie óór die Kategismus nie. Ek kom hierop terug maar plaas die woordjie ,oor" in die opskrif by voorbaat tussen aanhalingstekens. Die betekenis van die verhouding tussen Skrif en Kategismus is ook deur u self tereg so belangrik geag dat u dit as aparte onderwerp uitgelig en aan prof. W. D. Jonker toevertrou het.

1.2. Die onderwerp is meersydig. Dit impliseer onder andere die homiletiese vraagstelling: hoe kan die prediker aan die kategismuspreek telkens weer so 'n vorm gee en dit so aanbied dat dit die mense bly aanspreek? Ook die liturgiese vraagstelling: hoe kan mens aan die leerdiens bietjie meer kleur gee? En 'n pastoraalpsigologiese vraagstelling: watter weerstande moet die prediker deurbreek om telkens weer met die kategismuspreek tot die huidige kerkganger deur te dring? Hierdie en ander ,praktiese” kante van die onderwerp laat ek lê, in die wete dat ander teoreties en prakties beter daartoe in staat is om hulle vir $\mathrm{u}$ te belig.

1.3. Die probleemstelling. Artikel 48.4.2. van die Kerkorde van die Nederduits Gereformeerde Kerk bepaal: „Daar sal ook minstens twaalf keer per jaar in volgorde aan die hand van die Heidelbergse Kategismus gepreek word"'. En in artikel 68 van die Kerkorde van Die Gereformeerde Kerk in Suid-Afrika vind ons die volgende verhewiging van die probleem - miskien die rede waarom iemand uit hierdie kerkverband die ,antwoord" op u probleem moet gee? -: „Die bedienaars van die Woord moet op Sondag, gewoonlik in die tweede diens, die hoofinhoud van die Christelike leer soos vervat in die Heidelbergse Kategismus uitlê en soveel moontlik jaarliks afhandel volgens die Sondagsafdeling daarvan".

Die vraag is: kán dit? Móét die reëlmatige terugkeer van dieselfde stof nie weerstande oproep wat die kerkbesoek nadelig sal beinvloed nie?

Die punt van die argument in die vraagstelling is van tweërlei aard: kwantitatief en kwalitatief - kwantitatiewe en kwalitatiewe wanbalans in die verhouding tussen die stof vir die sogenaamde vryestof-en vir die kategismusprediking. Kwantitatief is die verhouding van die lengte van die Skrif tot die van die Kategismus sewentig tot éen. En kwalitatief is die geweldige plek wat aan 'n sekondêre bron teenoor die oorspronklike onuitputlike bron toegeken word ook buite verhouding. Kwantitatief benader lê die aksent van die onderwerp op die woord "dikwels". Kwalitatief benader lê die aksent van die onderwerp op die woord „Kategismus". Op beide 
maniere - deur herhaling en deur leerprediking - sou die prediker die mense kan wegjaag.

Ek gee vier antwoorde op die vraag van die onderwerp en daarna 'n slotstelling.

\section{Die eerste antwoord:}

2.1. Alleen as die Kategismusprediking Skrifprediking is, is dit moontlik om dikwels "oor" die Kategismus te preek sonder om die mense weg te jaag. Die reformatoriese kerk en teologie het steeds teenoor die opvatting van en die praktyk by Rome beklemtoon, dat die prediking geen leerstellige uiteensetting of dogmatiese sluitrede mag wees nie. Waar Gereformeerde teoloë oor die kategismusprediking handel, is dit opmerklik hoe daar steeds op gewys word dat dit Skrifprediking, Wóórdbediening moet wees. ${ }^{2}$

2.2. Dit beteken nie dat die Kategismus in die Kategismusprediking as 't ware buite spel geplaas word nie, maar wel dat bepaalde vorme van ,kategismusprediking" geoordeel is. Naamlik daardie vorm wat neerkom op blote parafrase van die teks van die Kategismus. Dán word die verbinding met die lewende bron, wat die water van die rivier in beweging en vars hou, afgesny.

Maar as die léwende band tussen die Kategismus en die Skrif ontbreek, die Kategismusprediking verdor en verstar en die mense wegbly, dan lê die fout nie by die kategismusprediking as sodanig nie maar by die prediker wat nie aan sy opdrag reg laat geskied nie.

Dit gaan in die kategismusprediking nie bloot om 'n napraat van die teks van die Kategismus nie. Skrifstudie moet die basis bly vir die uitlegging van die Christelike leer. Alleen dán sal die kategismusprediking ou en nuwe skatte aan die lig kan bring.

2.3. In die lig van bogaande moet daar op gewys word dat aan baie besware teen die kategismusprediking 'n valse teëstelling tussen Skrif en belydenis ten grondslag lê.

Soos wat mens Skrif en belydenis nooit mag vereenselwig nie (artikel VII Ndl. Geloofsbelydenis), mag mens die Bybel ook nie teen die Belydenis uitspeel nie. Mens sal met name in die Kategismus nie oor ' $n$ koue onbybelse klimaat kan kla nie. Dit bevat 'n samevatting van die Bybelse waarheid. Mens kan volgens Van Teylingen nie sê nie ,dass eine Predigt, die die grossen Themen der Bibel zusammenfasst und sie zu Bekenntnis und Lehre ausarbeitet, damit in dieser weise die Gemeende in den Raum der wahrhaft allgemeinen Kirche hineingeführt werde, als solche die Spannung, den Anspruch und die lebendige Kraft des Evangeliums vermissen lassen muss". ${ }^{3}$

\section{Die tweede antwoord:}

3.1. Alleen as die kategismusprediking prédiking bly is dit prinsipieel moontlik om dikwels "oor" die Kategismus te preek sonder om die mense weg te jaag. ${ }^{1}$

Die reformasie van die kerk in die sestiende eeu was ook die tyd van die herontdekking van die prediking, van die prediking in die Bybelse heilshistoriese sin van die woord. 
Die prediking is volgens die reformatore nie meer 'n uiteensetting van die gebooie en leerstukke van die kerk, of blote voorbereiding op die genade-ontvangs in die sakrament, soos by Rome nie. Nee, die prediking is sélf ,genademiddel”: as heilsverkondiging self ook gawe van die heil. Die preek is nie maar net toespraak ,oor" ,iets" nie, maar bedién-ing van die Evangelie, uitdeling van die veel. vuldige genade van God ( 1 Petrus $4: 10$ ). Daar gebeur iets in, met, deur die prediking sélf. Die prediking is die viva vox Dei. Die prediking is self 'n heilsgebeurtenis. ${ }^{5}$

Ook in die Kategismusprédiking gaan dit om die groot dade van God en hierdie dade van God moet gepréék, met die gesag van die heraut in Naam van sy Sender afgekondig, geproklameer word."

3.2. Dit is nie net so dat die kategismusprediking prediking móét wees nie, maar ons verder gaan en konstateer dat die eie aard of struktuur van die Kategismus sélf reeds daartoe verplig.

Die Kategismus is „onderwysing in die Christelike leer”. Dit wil die leer (didachè) van die Skrif deurgee. Maar hierdie leer is anders as dit wat ons gewoonlik onder "leer" verstaan. Dit geld reeds van die N.T. leer.

Die aard van die N.T. didachè word deur Herman Ridderbos ${ }^{7}$ as nie-spekulatief aangedui. Dit gaan enersyds uit van, bou voort op, is steeds onlosmakelik verbind met die kerugma - die aankondiging van die groot verlossingsdade van God in Jesus Christus. En andersyds is hierdie leer steeds gerig op die praktyk van die geloof.

Nie dat hierdie leer anti-intellektueel is nie; inteendeel, dit gaan om heilsmededeling in die vorm van onderwysing, saaklike uiteensetting, nadere toeligting en ontvouing van die sin en konsekwensies. Die kennis, insig en wysheid van hierdie leer word verkry deur middel van redenering, besinning, studie ens.

Maar ook die „Christelike leer" van die Kategismus is anders as dit wat ons gewoonlik daaronder verstaan. Vir ons is leer gewoonlik iets teoreties, iets abstraks, iets waarby ons nie konkreet by betrokke is nie, iets sistematies in die sin van afgeslote. Maar hierdie leer is lewensleer, praktiese waarheid, wat my wesenlik aangaan, terwyl die opbou (teologies beskou) so is dat die verskillende loci in deurlopende verweefdheid met mekaar, in verskillende samehange voorkom. Hierdie leer is die uitstalling van die rykdom van die Evangelie. Hierdie leer val onder die hoof van die beloftes van die Evangelie (vraag 22 Heid. Kat.). Hierdie leer is daarom tegelyk troos troos as "objektiewe" bobdskap, mededeling van die werklike heil, soos in Jesaja 40! Vandaar die sprekende titel van K. H. Miskotte se verklaring van die eerste twaalf sondae van die Kategismus: „De Blijde Wetenschap". ${ }^{8}$ J. T. Bakker praat van „de eenheid tussen directe pastorale taal en weloverwogen leer der kerk". ${ }^{9}$

In hierdie verband is dit ook verhelderend om daarvan kennis te neem dat die Kategismus oorspronklik integrerend deel van die liturgie was. Dit was deel van die Kerkorde van die Pfalz en het sy plek in hierdie Kerkorde tussen die doop- en nagmaalformulier gehad. ${ }^{10}$ 


\section{Die derde antwoord:}

4.1. Alleen as die kategismusprediking getrou bly aan die eie aard van die Kategismus, as ,eine zusammenfassende Auslegung des ganzen Schriftzeugnisses", 11 is dit moontlik om dikwels "oor" die Kategismus te preek sonder om die mens weg te jaag.

Die kategismusprediking is Skrifprediking in ' $n$ bepaalde sin van die woord: dit gaan daarin nie net oor 'n bepaalde teks of 'n enkele Skrifgedeelte nie (ook al is dit soms of baie keer prakties moontlik om 'n sondagafdeling onder die hoed van 'n enkele teks of perikoop te vang), maar oor die deurgaande leer van die Heilige Skrif oor ' $n$ bepaalde saak. Dit gaan om die eenheid, die samehange, ,die Ganzheit”, „die Totalität" van die Skrifopenbaring.12

Natuurlik, die regte sogenaamde ,vryestofprediking" mag nooit prediking van 'n geïsoleerde, uit verband gerukte teks wees nie. Daarom funksioneer die belydenis van die kerk, die Christelike leer, die samevatting van die Bybelse waarheid ook in die vryestofprediking, naamlik as spreekreël, ${ }^{13}$ of as strukturele deursnee, ${ }^{14}$ of as kerklike beslissinge oor die vraag wat in die prediking toelaatbaar is. ${ }^{15}$

Maar naas hierdie funksie van die belydenis in die vryest of prediking is daar ook en veral in ons tyd ' $n$ skreeuende behoefte aan "koers in die krisis”, aan ,onderwysing in die Christelike leer" in die bogenoemde sin van die woord. Dit te meer as mens bedink dat die kenmerkende van kettery juis is dat enkele aspekte, bepaalde fasette uit die geheel van die openbaring gelig word, wat só geaksentueer word dat die harmonie van die geheel, die ewewigtige nie-eensydigheid van die Skrif aangetas word. Kettery is 'n aantasting van die vólheid van Christus, die katolisiteit van die kerk, die katolieke vólheid van die waarheid. G. C. Berkouwer wys daarop dat die teologiese diskussies deesdae nou juis „niet zozeer over een incidenteel Schriftwoord (gaan nie), maar over de totale structuur van het bijbels getuigenis én de confessie". ${ }^{10}$

En as ons ten slotte bedink dat teologie en verkondiging onlosmaaklik aan mekaar verbind is, ${ }^{17}$ is dit ' $n$ dubbele onderstreping van die behoefte aan „onderwysing in die Christelike leer”.

4.2. Waar dit daarom gaan om saam met al die heiliges die breedte en lengte en diepte en hoogte van die liefde van Christus te begryp en waar dit hierdie Evangelie van die onnaspeurlike rykdom van Christus is wat verkondig moet word (Ef. $3: 18,8$ ), kan juis die kategismusprediking as besondere vorm van Skrifprediking ons bewaar vir individualisme van die prediker. ${ }^{18}$

Die vryestofprediking word bedreig deur die gevaar dat tekskeuse, uitlegging en toepassing eenvoudig deur die voorliefde(s) van die prediker oorheers word. Wanneer tekskeuse on inhoud van die preek egter nie eenvoudig aan die individualistiese keuse van die prediker oorgelaat word nie, kan dit sy vryheid skynbaar aan bande lê, maar in werklikheid lê dit sy willekeur aan bande.

\section{Die laaste antwoord:}

5.1. Alleen as die kategismusprediking die lewende Woord van 
God is in die sin dat dit gerig is op my, in my lewe en omstandighede, is dit moontlik om dikwels "oor" die Kategismus te preek sonder om die mense weg te jaag. In die kategismusprediking moet die verbinding met die Skrif as blywende voedingsbron in stand gehou word, maar - in ooreenstemming met die openbaring van die God van die Bybel as God-met-ons, met die aard van die Skrifopenbaring as die verhaal van die omgang van die lewende God met die lewende mens én met die heilshistoriese karakter van die prediking - moet die verbindingskanale met die lewende, konkrete mens ook oop bly. Die kategismusprediking mag na beide kante toe nie abstraheer nie !

Aangesien regte kategismusprediking nie blote parafrase van die Kategismusteks is nie, maar verkondiging van die léwende Wó́rd in sy samehange en verbande, is dit per definisie bedoel vir die mens in sy eie tyd-en lewensomstandighede. Só is daar in die kategismusprediking dus nie alleen ruimte vir die resultate van die voortgaande Skrifondersoek nie, maar ook vir die nuwe, eietydse vrae.

5.2. Dít hou in dat die prediker 'n ope oog vir die historiese bepaaldheid en tydgebondenheid van die Kategismus moet hê. ${ }^{19} \mathrm{Hy}$ moet daarmee rekening hou dat die vrae van vandag glad nie of nie volledig deur die historiese konfessies beslis word nie. ${ }^{\text {*0 }}$ Ook is daar sake wat in die Kategismus uitvoerig aandag kry wat vandag feitlik geen saak meer is nie - byvoorbeeld die sondae oor die nagmaal. Dit sal tans anders, korter, in die prediking aan dic orde kom.

Hierdie erkenning is geen devaluasie van die kerklike belydenis nie, maar 'n positiewe waardering van die heerlike waarheid dat die Here God mý op die oog het.

Vandaar ook die persoonlike gerigtheid van die Kategismus reg van die begin af! Die omwenteling wat die reformasie in die sestiende eeu in hierdie opsig teweeggebring het moet juis in die prediking van die Kategismus wat daardeur gestempel is, voortdurend blyk. Die massamens van ons tyd het nie minder behoefte daaraan as die verkerklikte nommers van destyds nie.

Só sal mens met die konfessies uit die verlede vrugbaar in die hede kan staan, sonder om die weg van die toekoms van die lewende God te blokkeer en sonder dat die tragedie van die protestantse Skolastiek, wat nie meer opgewasse was teen die gees van die nuwe tyd nie, hom in ons tyd van voortgaande sekularisasie sal herhaal.

5.3. Alleen as ons ' $n$ ope oog het vir die historiese bepaaldheid van die Kategismus, sal ons aan die Kategismus sélf reg laat geskied. Ek noem 'n paar voorbeelde: Sondag 22, waarin die Grieks-wysgerige onderskeid van siel en liggaam geleer sou word: Die Kategismus gee egter aan die Bybelse verwagting, wat bely word, uitdrukking met die begrippe van sy tyd.

Die belydenis van die voorsienige leiding van God in Kategismus sondag 10, veral vraag 27: Geabstraheer van die tyd waarin bely is, word hier 'n soort al-voorsiening van God geleer, waarby die geskiedenis en die verantwoordelikheid van die mens uitval en wat 'n dodelike soort van spanninglose berustingsgeloof tot gevolg moet hê. 
Maar dit is bely in ' $n$ tyd wat die brandstapel 'n konkrete moontlikheid en werklikheid was en in 'n tyd wat die mense as 't ware aan onbeheerbare natuurkragte uitgelewer was. Met ander woorde; alles behalwe ' $n$ abstrakte belydenis van die alvoorsiening van God. ${ }^{21}$

\section{Ten slotte:}

Ten slotte maak ek die stelling: ás daar van 'n betekenisvolle weerstand teen die kategismusprediking sprake is, wat miskien in die bywoning van die tweede diens tot uitdrukking sou kom, moet die remedie allereers gesoek word in 'n eerherstel van die "Christelike leer" onder die predikers en nie in eksperimente met die tweede diens nie.

Hierdie stelling hou die belydenis van 'n prediker van die Kategismus in, dat die preek - kategismuspreek én vryestofpreek nie vanselfsprekend die mense wegjaag nie.

\section{Aanhangsel:}

Is „uitbreiding" van artikel 68 Kerkorde dalk die oplossing?

Die voor-die-hand-liggende praktiese vraag of die reëlmatige herhaling van dieselfde leerstof nie weerstande moet oproep nie, is in die verlede en word ook vandag sporadies maar tog daadwerklik beantwoord deur ook die ander reformatoriese belydenisskrifte as basis aan die „leerprediking” ten grondslag te lê.

Wat die verlede betref: Willem te Water meld onder andere dat Balthasar Bekker $(1634-1698)^{22}$ te Oosterlittens een keer en in Amsterdam twee keer belydenispredikasies (oor die Nedl. Geloofsbelydenis) gehou het, waarin "den draed derzelven stipt gevolgd" is ${ }^{23}$ en dat hy in 1696 'n preekbundel oor hierdie belydenispredikasies uitgegee het. ${ }^{24}$ Self pleit Te Water ${ }^{25}$ ook vir „Belijdenis-predikatiën” of „publyke weeklyksche Catechizatiën” oor die Nedl. Geloofsbelydenis voor die nagmaal, en wel op grond van die woorde in artikel 35 Nedl. Geloofsbelydenis: „ons doen daar ( = aan die nagmaal) belydenis van ons geloof en van die Christelike godsdiens". So iets was destyds in Delft selfs 'n gebruik.

Wat die hede betref: Op ons laaste Nasionale Sinode-sitting was daar ' $n$ beskrywingspunt om artikel 68 Kerkorde uit te brei tot aldrie die formuliere van eenheid, alhoewel die Kategismus in die voorgestelde formulering die prerogatief behou. ${ }^{28}$ Alhoewel daar nie aan die beskrywingspunt gevolg gegee is nie, is dit bekend dat verskeie van ons predikante die Nedl. Geloofsbelydenis by wyse van afwisseling vir die ,leerdiens" gebruik het.

Die vraag wat ons hier voorgelê word lui: is dit 'n werklike uitweg uit die skynbare probleem van ons onderwerp?

7.1. Wat die verlede betref was daar blykbaar „belydenispredikasies" aan die hand van die Nedl. Geloofsbelydenis. Maar afgesien daarvan dat dit blykbaar net by wyse van uitsondering plaasgevind het en dit geen reël was nie, is dit voorts nog die vraag of daar in sulke uitsonderingsgevalle dieselfde onder verstaan is as 
wat artikel 68 Kerkorde „uitlegging” en die Kategismus „onderwysing" in die Christelike leer noem.

Dit is en bly históries merkwaardig dat artikel 68 Kerkorde juis die Heidelbergse Kategismus noem en nie die Nedl. Geloofsbelydenis met die Dordtse Leerreëls as latere uitbreiding van artikel XVI Nedl. Geloofsbelydenis nie. Daar was aanvanklik blykbaar wel 'n alternatief, maar dit het net op Calvyn se Kategismus van Genève betrekking gehad. Maar van 'n uitbreiding van die bepaling soos ons dit van die Kerkorde van die Pfalz 1563 af ken, na die ander belydenisskrifte was daar (sover ek kon vasstel) nie op 'n provinsiale- of nasionale sinode sprake nie. En dit terwyl daar van die begin af, in die lig van die gereelde klagtes oor verskraling en agteruitgang in die kennis van die belydenis van die kerk, alle rede voor was. Die sinodes het egter ander weë gegaan om die gevaar van 'n latente, verborge, nie meer lewendig - funksionerende belydenis te bestry.

Mens kan ook nie sê nie: dit lê voor die hand dat juis die kategetiese leerboek vir die doel van die prediking gebruik is, aangesien die kategismusprediking histories uit die kategese van die gemeente gegroei het. Históries kan mens nie so stellig spreek oor wat uit wat gegroei het nie. ${ }^{27}$ Verder is dit ' $n$ feit dat ander reformatoriese belydenisskrifte van die begin af ook in die kerk gefunksioneer het, maar as reël nie en in elk geval nie met die sanksie van 'n meerdere vergadering nie vir die doel van die prediking in die leerdiens aangewend is nie.

7.2. Wanneer mens die pleit wil voer vir 'n offisiële of onoffisiële uitbreiding van artikel 68 Kerkorde, moet jy uiters versigtig omgaan met die argument dat die drie formuliere van enigheid mekaar tog onderling aanvul en dit in die prédiking tog om die verkondiging van die héle raad van God moet gaan.

Impliseer hierdie redenasie nie dat die prediking aan die hand van één belydenisskrif onvolledig sou wees nie? Gaan hierdie opvatting nie uit van 'n prediking van die Kategismus-teks as sodanig nie? En gaan hierdie siening op die belydenis nie mank aan 'n kwantitatiewe opvatting van die raad van God, die waarheid of die leer nie? ${ }^{28}$ Word in Handelinge $20: 27$ met die ",hele raad van God" iets anders bedoel as "die koninkryk van God verkondig” in vers 25 van dieselfde hoofstuk?

Mens moet in gedagte hou dat die Gereformeerde reformasie in onderskeid van die Lutherse ontwikkeling geen Formula Concordia of „Konkordiënbuch" ken nie. Uit die praktyk van oor en weer ondertekening van belydenisskrifte blyk dat die Gereformeerde reformasie geen eenvormigheid nie, maar wel eenheid in die belydenis nagestreef het. ${ }^{29}$

7.3. Die antwoord op die vraag waarom 'n uitbreiding van artikel 68 Kerkorde geen oplossing bied nie, lê myns insiens in die struktuurverskille tussen die belydenisskrifte onderling.

7.3.1. Reeds ten opsigte van die verhouding van die N.T. homologia tot die historiese konfessies is daar sprake van 'n steeds toenemende teologiese refleksie en gevolglik van toename in omvang 
van laasgenoemde, wat sy eie probleme in die prediking en die liturgie meebring. ${ }^{30}$

Maar ook ten opsigte van die reformatoriese konfessies moet die struktuurvraag aan die orde gestel word, met name die struktuurverskille tussen die Heidelbergse Kategismus en die Nedl. Geloofsbelydenis (plus Dordtse leerreëls). Vrae wat gestel moet word is onder andere: wanneer is hul opgestel, waarom is hulle opgestel, vir wie was hulle in die eerste plek bestem, wat was hul plek in die kerklike lewe ens. Om sulke vrae te stel is nie iets nuuts nie. A. Kuyper byvoorbeeld het 'n ope oog gehad vir hierdie verskille in struktuur tussen die Kategismus en die Nedl. Geloofsbelydenis. ${ }^{31}$

7.3.2. Die Heidelbergse Kategismus was in sy ontstaan vir eie kring bestem, terwyl die Nedl. Geloofsbelydenis 'n verdedigingsgeskrif was vir die buitewêreld (die destydse owerheid) bestem.

Die Kategismus is in sy ontstaan en oogmerke nie 'n stuk abstrakte polemiek of teologie nie, maar integrerende deel van die kerklike lewe, die kerklike liturgie. ${ }^{32}$ Nie dat die Kategismus in onderskeid van die Nedl. Geloofsbelydenis sonder enige teologiese refleksie is nie. Hulle staan nie téénoor mekaar as nie-teologies en teologies nie. Dit is volgens G. C. Berkouwer verkeerd om te sê dat die Kategismus vir die hart en die Nedl. Geloofsbelydenis vir die hoof is. ${ }^{33}$ Ook die Kategismus het merkbaar in 'n teologies-polemiese situasie ontstaan, terwyl andersyds ook in die Nedl. Geloofsbelydenis die heil eweseer in die middelpunt staan.

Ook is dit verkeerd om die Kategismus en die Geloofsbelydenis soos by M. A. Gooszen ${ }^{34}$ téénoor mekaar te stel as antroposentriessoteriologies én teosentries. ${ }^{35}$

Maar die Kategismus is „eenvoudiger”, prakties-opbouend, pastoraal gerig in vorm. Mens kan sê die verskille het nie soseer op die geloofsinhoud betrekking nie, maar op die uitdrukkingsvorme. ${ }^{36}$ Dit blyk volgens G. C. Berkhouwer onder andere uit 'n vergelyking tussen die Heid. Kategismus Sondae 25-30 en die Nedl. Geloofsbelydenis artikel 33-35; Kategismus Sondag 6 met Geloofsbelydenis artikel 19.

Daar is verskille in metode en indeling. Die Kategismus volg 'n indeling ${ }^{37}$ wat ons in die Romeinebrief terugkry, alhoewel nie as absolute sisteem nie. En die raamwerk word grotendeels tradisioneel gevul deur die sober indrukwekkende behandeling van die twaalf artikels, die tien gebooie en die Onse Vader. Die Kategismus plaas ons direk in 'n Bybelse klimaat. Dit volg nie soos die Nedl. Geloofsbelydenis die klassieke volgorde van die teologie (teologie, antropologie, christologie, soteriologie, ekklesiologie, eskatologie) nie. Teologies beskou kom die verskillende loci wel voor, maar $^{38}$ in deurlopende verweefdheid met mekaar en in verskillende verbande. Dit is saaklik ook juis, in ooreenstemming met die belydenis van die aard van die eenheid van die Skrif. ${ }^{30}$

7.3.3. Dit is hier nie die plek om nader in te gaan op die betékenis van die struktuur van die belydenis vir die prediking nie. ${ }^{40}$ Ek volstaan met die gevolgtrekking waartoe J. T. Bakker kom: „Nooit is de pastorale aard van de bijbelse leer naar mijn besef zo tot uitdrukking gebracht als in dit geschrift geschied is. Er bestaat geen 
kerkelijk belijdenisgeschrift, waarvan de vroomheid in de diepe zin van het woord zo wezenlijk is als hier het geval is. Daarom, áls er zoiets als een leerboek der kerk moet zijn dán weet ik niets, dat ik naast de catechismus zou kunnen leggen. Zodat ik er ook geen begrip voor kan opbrengen wanneer men zegt: laten we het nu eens een jaar met de Nederlandse Geloofsbelijdenis proberen. Ik vermoed, dat wie het probeert er spoedig van terug zal komen. Want het is juist de unieke eenheid tussen directe pastorale taal en weloverwogen leer der kerk, die de catechismus tot nu toe in stand hield". 41

7.3.4. Die struktuurverskille tussen die konfessies leer ons in die onderhawige saak myns insiens dat die Nedl. Geloofsbelydenis (plus Dordtse leerreëls) nie in dieselfde sin as die Heid. Kategismus vir die prediking bedoel is en hom daarvoor leen nie - 'n siening wat deur die geskiedenis onderstreep word.

Ds. H. Dijkstra, Paarl.

1 Lesing voor Konfes, studentevereniging aan die Kweekskool te Stellenbosch, 26 April 1974, met 'n aanhangsel van vroeër datum.

2 A. Kuyper: Encyclopaedie der Heilige Godgeleerdheid. Deel III. Kampen 19.92, p. 501; K. Dijk: De dienst der prediking. Kampen 1955, p. 406 e.v.; E. G. van Teylingen: Der Katechismus in der Predigt. In: Handbuch zum Heidelberger Katechismus. Hrsg. Lothar Coenen. Neukirchen 1963, p. 190 e.v.

3 E. G. van Teylingen: a.w., p. 193.

4 Vgl. die aksent wat K. Dijk: a.w., p. 410 in navolging van T. Hoekstra hierop lê.

$5 \mathrm{Vgl}$. Heid. Kategismus vraag 65 (die Heilige Gees wat die geloof in ons harte werk deur die verkondiging van die heilige Evangelie) en vraag 83 en 84 (die hemelryk wat deur die prediking van die heilige Evangelie oop- $\mathrm{en}$ toegesluit word).

6 Vgl. J. T. Bakker: Eschatologische prediking by Luther. Kampen 1964, p. 9; idem: Vernieuwing van de prediking by Rome. G.T.T. Jg. 64, nr. 3, p. 147 e.v.v.; V. E. d'Assonville: Kerk en Prediking, s.j., p. 4 e.v.; B. A. Müller: Die lewende Woord aan die mens van die hede (Dis. V.U.), Zaandijk 1961, hfst. VII.

7 Herman Ridderbos: Heilsgeschiedenis en Heilige Schrift van het Nieuwe Testament. Het gezag van het Nieuwe Testament. Kampen 1955, p. 134 e.v.

8 Toelichting op de Heidelbergse Catechismus. Deel I. Franeker s.j.2 Vgl. p. 10.

9 J. T. Bakker: De Catechismuspreek. Geref. Weekblad, Jg. XVII, nr. 8 (25.8.61), p. 60 .

10 Karl Barth: Die christliche Lehre nach dem Heidelberger Katechismus. Zürich 1948, p. 17.

11 E. G. van Teylingen: a.a., p. 194.

12 E. G. van Teylingen: a.w., p. 194.

13 O. Noordmans: Herschepping. Amsterdam 19562, p. 23, 24; A. A. van Ruler: Hoe functioneert de belijdenis? Wageningen s.j. (1954), p. 19 (tans in: Theologisch Werk. Deel VI. Nijkerk 1973).

14 o. Noordmans: Zoeklichten. Amsterdam 1949, p. 33, 35, 41, 42.

15 C. W. Mőnnich: De weg en de wegen. Amsterdam 1949, p. 62, 165. Vgl. hier in sy geheel J. T. Bakker: Het dogma tussen tekst en preek. Kampen 
1969; en vir die plek van die dogma tussen teks en preek O. Noordmans: Zoeklichten, p. 43 en 44.

16 G. C. Berkouwer: Vragen rondom de belijdenis. G.T.T. Jg. 63, nr. 1 (Februari 1963), p. 10.

17 'n Goeje illustrasie van hierdie stelling is Joachim Konrad (herausgeber); Die Evangelische Predigt. Grundsätze und Beispiele, homiletischer Analysen, Vergleiche und Kritiken. Bremen 1963.

18 Vgl. J. T. Bakker: a.a. in Geref. Weekblad; E. G. van Teylingen: a.a., p. 193.

19 Sien A. Kuyper: Calvinisme en revisie. Amsterdam 1891, p. 5; H. Bavinck: Modernisme en orthodoxie. Kampen 1911, p. 35; G. C. Berkouwer: Der Weg durch die Zeit. In: Handbuch zum Heidelberger Katechismus, hrsg. Lothar Coenen, p. 256 e.v.; idem, Verontrusting en Verantwoordelijkheid. Kampen 1969, p. 130 e.v.; Gerhard Ebeling: Die Geschichtlichkeit der Kirche und ihrer Verkündigung als theologisches Problem. Tübingen 1954.

20 Vgl. E. G. van Teylingen: a.w., p. 195/6; A. F. N. Lekkerkerker: Gesprekken over de Heidelberger. Wageningen 1964, p. 151 E.v.

21 Vgl. my artikel: "... (dat) alle dinge... uit sy Vaderlike hand ons toekom". Kerknuus. Jg. 18, no. 4 (April 1974), p. 7.

22 Sien ter plaatse Christelijke Encyclopedie. Deel I. Kampen 1956.

23 Willem te Water: Tweede Eeuw-getijde van de geloofsbelijdenisse der Gereformeerde Kerken van Nederland. Middelburg 1762, p. 174. Ek dank hierdie inligting aan dr. C. van der Waal.

24 Id., p. 172.

25 Id., p. 211.

26 Handelinge 1973, p. 338. Die sinsnede lui: „... die hoofinhoud van die Christelike leer soos vervat in die Belydenisskrifte (veral die Heidelbergse Kategismus)..." Blykbaar na analogie van artikel $\mathrm{XI}$ van die nuwe Kerkorde van die Nedl. Hervormde Kerk: „.... in de leerdiensten kan ook gehandeld worden over belijdenisschriften, in het bijzonder de H.C.". Ook by hierdie artikel verklaar Th. $H$. L. Haitjema onder andere dat die Kategismus daardeur aanbeveel word as "meer geëigend als leidraad bij de actuele bediening des Woords dan de andere formulieren van enigheid onzer kerk", Th. H. L. Haitjema: De Heidelbergse Catechismus als klankbodem en inhoud van het actuele belijden onzer kerk. Wazeningen 1962, p. 14.

21 Vgl. K. Dijk: a.w., p. 408.

28 Vgl. daarteen H. Bavinck: Gereformeerde Dogmatiek. Deel I. Kampen $1928^{4}$, p. 583; G. C. Berkouwer: Verontrusting en verantwoordelijkheid, p. 146 e.v.

29 Vgl. W. Nijenhuis: Calvijn en de Augsburgse Confessie. Nedl. Theol. Tijdschrift, Jg. 15 (1960-1961), p. 416 e.v.; idem: Calvinus Oecumenicus. 's-Gravenhage 1959.

$30 \mathrm{Vgl}$. H. Gollwitzer: Die Bedeutung des Bekenntnisses für die Kirche. In: Hören und Handeln. Festschrift für Ernst Wolf. München 1962, o.a. p. 163/4; Edm. Schlink: Die Struktur des dogmatischen Aussage als ökumenisches Problem. In: Der kommende Christus und die kirchlichen Traditionen. Göttingen 1961, p. 24 e.v.; T. F. Torrance: Das Problem des theologischen Aussage heute. T.Z. XIX (1963), p. 318 e.v.; W. Joest, W. Pannenberg e.a.: Dogma und Denkstrukturen. Gottingen 1963; G. C. Berkouwer: Vragen rondom de belijdenis, p. 10 e.v.; idem: Verontrusting en verantwoordelijkheid, p. $142 / 3$. 
31 A. Kuyper: Revisie der revisie-legende. Amsterdam 1879, p. 80/1.

32 Vgl, bo 3.2.

33 G. C. Berkouwer: Is de Catechismus verouderd? (II). In: Gereformeerd Weekblad, Jg. XI, nr. 8 (19-8-1955), p. 57.

34 Vgl. byvoorbeeld M. A. Gooszen: De Heidelbergsche Catechismus. Textus Receptus. Met toelichtende teksten. Leiden 1890, p. 149 e.v.

35 Hierteen G. C. Berkouwer: Het werk van Christus. Kampen 1953, p. 26, 28, 24937, 376; idem: De wederkomst van Christus. Deel I. Kampen 1961, p. 267.

36 G. C. Berkouwer: Der Weg durch die Zeit. In: Handbuch zum Heidelberger Katechismus, p. 255.

37 Vir die indeling, metode en struktuur van die Kategismus vgl. o.a. 0. Weber: Analytische Theologie. Zum Geschichtlichen Standort des Heidelberger Katechismus (1963). In: Die Treue Gottes in der Geschichte der Kirche. Ges. Aufsătze II. Neukirchen 1968, p. 131 e.v.

$38 \mathrm{Vgl}$. bo 3.2 .

39 Paul Jacobs: Theologie Reformierter Bekenntnisschriften in Grundzügen. Neukirchen 1959 , p. 60.

Neukirchen 1959, p. 60. In hierdie lyn lê m.i. die wysiging wat Calvyn aanbeveel het vir die inset van die Paryse Geloofsbelydenis van 1557 (waarmee ons artikel I van die Nedl. Geloofsbelydenis ooreenkom): i.p.v. 'n begin na analogie van die Middeleeuse teologie oor die eienskappe van God, die pastorale uitgangspunt van die openbáring van die lewende God. Vgl. C. Augustijn: Kerk en Belijdenis, Kampen 1969, p. 36; egter ook my: "God" (gebruiksaanwysing by 'n woord). Die Kerkblad 15.5.1974, p. 9, 11.

40 Daaroor het ek by geleentheid voor die dogmatiese werkgemeenskap van die teologiese studente te Potchefstroom, 12.3.1971, gepraat.

41 J. T. Bakker: a.a. in Geref. Weekblad, p. 60. 